\title{
The role of plant odours in the leafminer Liriomyza sativae (Diptera: Agromyzidae) and its parasitoid Diglyphus isaea (Hymenoptera: Eulophidae): Orientation towards the host habitat
}

\author{
YUN XIAN ZHAO and LE KANG*
}

State Key Laboratory of Integrated Management of Pest Insects \& Rodents, Institute of Zoology, Chinese Academy of Sciences, 19
Zhongguancun Road, Haidian, Beijing 100080, China; e-mail: zhaoyx@panda.ioz.ac.cn; lkang@panda.ioz.ac.cn

Key words. EAG, leafminer, Liriomyza sativae, parasitoid, Diglyphus isaea, plant odours

\begin{abstract}
Electroantennogram responses of the polyphagous leafminer Liriomyza sativae and its generalist parasitoid Diglyphus isaea to host and non-host plant odours of $L$. sativae were investigated. The odours of healthy leaves can elicit distinct EAG responses in $L$. sativae. The EAG responses to the odours of the host plants, bean and tomato, were stronger than to non-host plants, Chinese rose and morning glory. Neither healthy host nor non-host plants of the leafminer elicited distinctive EAG responses in the parasitoid, $D$. isaea. Odours of physically damaged leaves, no matter whether of host or non-host plants, increased strongly the EAG responses of the leafminer and its parasitoid. We compared the EAG responses of $D$. isaea to bean leaves of different status. The odour of mined leaves elicited distinct EAG responses, which were weaker than those of physically damaged ones. No differences were detected in the EAG response to leaves with empty mines, healthy leaves or an air control. The role of plant odours in host location of the leafminer and its parasitoid is discussed.
\end{abstract}

\section{INTRODUCTION}

The leafminer, Liriomyza sativae is a polyphagous herbivore, which attack a variety of vegetable and ornamental crops (Parrella, 1987; Kang, 1996). The leafminer larvae are obligatory internal plant feeders. They feed in leaf mesophyll tissue and form a serpentine mine. Chemical control of agromyzid leafminers has resulted in the development of insecticide resistance in Liriomyza population and the elimination of their natural enemies, leading to an increasing control problem. The ectoparasitoid, Diglyphus isaea Walker is used in biological control of agromyzid leafminers in greenhouses (Van Lenteren \& Woets, 1988). Female parasitoids oviposit in the last larval stages of the leafminers (Minkenberg \& Van Lenteren, 1986). They use several species of Liriomyza, including $L$. sativae, as hosts. Although $D$. isaea can parasite different leafminers on different crops, the uneven distribution of parasitoids among crops has been investigated in the field (Zehnder \& Trumble, 1984; Johnson \& Hara, 1987; Schuster et al., 1991; Salvo \& Valladares, 1997). It has been suggested that parasitoids favour a range of insect hosts related rather to a particular plant or habitat than to phylogenetically related insect hosts (Askew \& Shaw, 1978). In the tritrophic interactions involving plants, leafminers and $D$. isaea, both the host and its parasitoid are generalists. It is critical to know which best host plant matches the natural enemy used in biological control of the leafminers.

Plant volatiles are employed by both herbivores and their natural enemies in searching for both food and oviposition place (De Moraes et al., 2000). Several studies have shown that insect herbivores are attracted by the odours of the host plants (Cosse et al., 1995; Light et al., 1988; Guerin \& Visser, 1980). Plants release herbivore induced volatiles (HIVs) as a result of feeding by herbivores, which are used by the natural enemies to locate hosts (De Moraes et al., 1998, Turlings et al., 1990, Turlings et al., 1991). A previous study has demonstrated that female $D$. isaea were strongly attracted to the odours arising from the infested bean plants (Finidori-Logli et al., 1996). Others have noted that the release of plant compounds is highly variable across plant species and varieties and is also sensitive to the species of herbivore (Dicke et al., 1990; Turlings et al., 1990, 1991; Takabayashi et al., 1991; De Moraes et al., 1998). De Moraes et al. (1998) demonstrated that plant emissions could transmit herbivore species-specific information that is detectable by parasitoids. Both tobacco and cotton produced distinct blends of volatiles in response to damage by two closely related herbivore species, Heliothis virescens Fabricius and Helicoverpa zea Boddies. The specialist parasitic wasp Cardiochiles nigriceps exploits these differences to distinguish infestations by its host, $H$. virescens from those by non-hosts. Although there are numerous studies on the behavioural responses of parasitoids to plant volatiles, only a few have investigated the physiological responses to these chemical cues.

In this paper we report the olfactory responses of the leafminer $L$. sativae and its parasitoid $D$. isaea to the odours of different plants using electroantennograms. We investigate the role of plant odours in their long-range host habitat preferences.

\footnotetext{
* Corresponding author.
} 
TABLE 1. Plants used in EAG test.

\begin{tabular}{llc}
\hline Family & \multicolumn{1}{c}{ Scientific name } & $\begin{array}{c}\text { Common } \\
\text { name }\end{array}$ \\
\hline Leguminosae & Phaseolus vulgaris $\mathrm{L}$. & $\begin{array}{c}\text { Common } \\
\text { bean }\end{array}$ \\
Solanaceae & Lycopersicon esculentum Mill. & Tomato \\
Cucurbitaceae & Cucurbita pepo L. & Squash \\
Rosaceae & Rose chinensis & Chinese rose \\
Convolvulaceae & Pharbitis purpurea $(\mathrm{L}$.$) Voigt$ & $\begin{array}{c}\text { Morning } \\
\text { glory }\end{array}$ \\
\hline
\end{tabular}

\section{MATERIALS AND METHODS}

Plants. All plants (Table 1) except beans were grown in an experimental field at the Institute of Zoology, Chinese Academy of Sciences. Beans (Phaseolus vulgaris L.) were planted in pots in the laboratory. Plant samples were taken from the leaf petiole so as to minimize the number of cut surfaces through which volatiles from within the tissues might escape. Cartridges were loaded with a fresh sample of each plant every morning, left at room temperature and used throughout the day. When physically damaged leaves were required, they were cut by a knife before the experiments.

Leafminer. $L$. sativae was reared as described by Zhao \& Kang (2000). They were reared on beans (Phaseolus vilgaris L.) at $25 \pm 1{ }^{\circ} \mathrm{C}$ with a photoperiod of $14 \mathrm{~L}: 10 \mathrm{D}$ and relative humidity $60 \%$. Only unmated females were used in the experiments.

Parasitoid. D. isaea were collected as pupae from the field. They were separated from the mines and maintained in a climate chamber at $25 \pm 1{ }^{\circ} \mathrm{C}$ with a photoperiod of $14 \mathrm{~L}$ : $10 \mathrm{D}$ and $60 \%$ relative humidity. On the day of emergence, individual adults were isolated in tubes with $10 \%$ honey-water as a food source Again, only unmated females were used in the experiments.

\section{Electroantennogram (EAG)}

Antenna preparation. Antennae of $L$. sativae were prepared using the method described by Zhao \& Kang (2001, 2002a). The test insect's head was removed, and the tip of the arista was cut off. EAGs were recorded using electrolyte-filled (Ringer's) glass capillary $\mathrm{Ag}-\mathrm{AgCl}$ electrodes; the reference electrode was positioned into the haemocoel of the cranial cavity, while the recording electrode was connected to the cut arista. In preparing the antenna of the parasitoid, the head of the insect was removed, and the tip of the antenna was cut off. The reference electrode was pierced in the haemocoel of the cranial cavity, while the recording electrode was connected with the cut antenna. The ventral surface of the antenna was orientated to face the odour stream. Only the left antenna from each insect was used.

Odour delivery system. The odour source cartridges consisted of glass tubes $70 \mathrm{~mm}$ long and $25 \mathrm{~mm}$ diameter containing $2 \mathrm{~g}$ fresh weight of plant material. The odour stimuli include: (1) healthy, intact leaves; (2) physically damaged leaves; (3) mined bean leaves infested with 2 nd-instar $L$. sativae larvae feeding; and (4) bean leaves with empty mines. The cartridges were sealed at each end with a rubber stopper wrapped in a piece of aluminium foil. A short length of $7 \mathrm{~mm}$ diameter glass tube was passed through each end of the rubber stopper to allow air to move through the cartridge.

A constant flow (1.0 litre/min) of charcoal-filtered and humidified compressed air was passed over the antenna through a disposable nozzle positioned about $1 \mathrm{~cm}$ from the antenna. Test substances were introduced into the air stream by inserting the tubing of the cartridge into the hole of the delivery tube and injecting the cartridge contents quickly and smoothly. The stimulation duration was $0.2 \mathrm{sec}$. Each stimulus was followed by an interval of about 90 seconds of clean air. The signal was amplified $10 \times$ by a Universal AC/DC amplifier UN-06 and viewed on the computer screen. EAGs were recorded with a Syntech EAG recording system for Windows (Version 2.6).

Experimental procedure. For each stimulus, EAGs were recorded from at least ten antennae. After every third to fifth test, a "control" stimulation (an empty cartridge) and "standard" stimulation (using fresh cartridges impregnated with $1 \mu 1$ of $95 \%$ hexan-1-ol) were presented. EAGs of test plants were evaluated by measuring the maximum amplitude of negative deflection $(-\mathrm{mV})$ elicited by a given stimulus and then subtracting the amplitude of the response of the preceding control. The millivolt responses to all plants were converted to percentage values of the response to the accompanying standard. EAG data were subjected to ANOVA and means were compared by Tukey's test (using SPSS 8.0).

\section{RESULTS}

\section{EAG responses of $\boldsymbol{L}$. sativae to different plants odours}

Mean responses of female $L$. sativae to the hexan-1-ol standard $(95 \%, 1 \mu 1)$ were $-1.07( \pm 0.04 \mathrm{SE}) \mathrm{mV}$. There were differences in the magnitude of the EAG responses of $L$. sativae to the odours of different plants $(P<0.05)$ (Fig.1). Among the EAG responses to healthy leaves, $L$. sativae were significantly more responsive to bean and tomato. The EAG response to squash was less pronounced. The lowest magnitude of responses were observed for Chinese rose and morning glory. All of the healthy plants elicited greater EAG responses to $L$. sativae than did controls $(P<0.05)$. Much higher EAG responses were detected to physically damaged leaves for all the test plants. The EAG responses to physically damaged leaves was similar for morning glory, Chinese rose and squash. Damaged leaves of tomato elicited a response of higher magnitude.

\section{EAG responses of $\boldsymbol{D}$. isaea to different plants odours}

The mean response of female $D$. isaea to the hexan-1-ol standard $(95 \%, 1 \mu \mathrm{l})$ was $[-1.63( \pm 0.12 \mathrm{SE}) \mathrm{mV}]$. Although the magnitude of the EAG responses to the healthy leaves of tomato was higher than to other healthy leaves, they were no higher than the controls (Fig. 2, $P<$ 0.05). However, mechanically damaged leaves elicited high EAG responses from the parasitoids (Fig. 2) with damaged bean leaves eliciting responses of the highest magnitude. The EAG responses to damaged tomato and Chinese rose were higher than those to the damaged squash $(P<0.05)$.

\section{EAG responses of $\boldsymbol{D}$. isaea to bean leaves in different status}

Fig. 3 shows the EAG responses of female $D$. isaea to bean leaves of different status. The EAG responses of the parasitoid to the healthy leaves and leaves with empty mines showed no significant difference to the air control. Infested leaves with 2 nd-instar $L$. sativae larvae feeding within them elicited detectable responses to $D$. isaea, but 


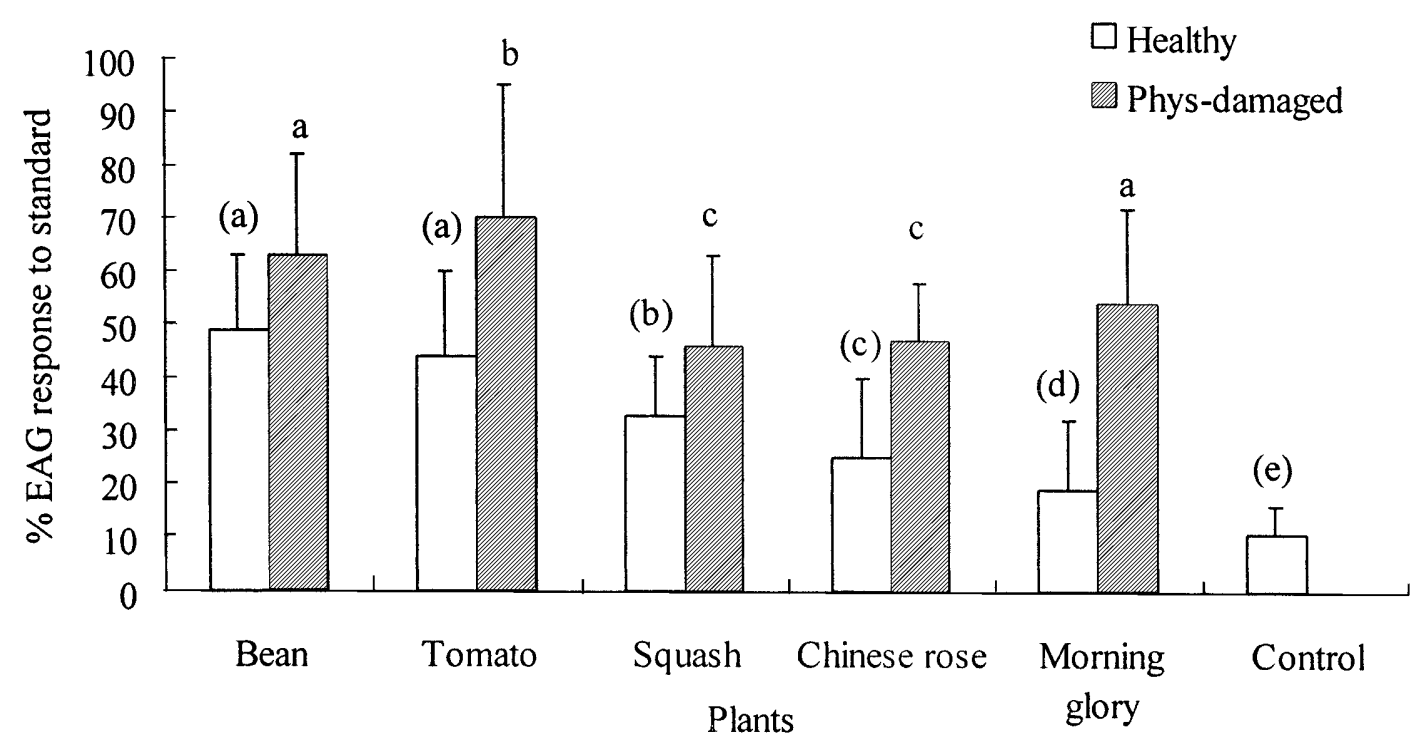

Fig. 1. EAG responses of $L$. sativae to the odours of different plants $(\mathrm{n}>10)$. The vertical line indicates standard deviation. Letters within the brackets represent significant differences of EAG responses between healthy plants and controls. Letters without brackets represent significant difference of EAG responses to physically damaged plants. Means with the same letter on the bar are not significantly different $(P<0.05)$.

the magnitude was less than that elicited by the mechanically damaged leaves $(P<0.01)$.

\section{DISCUSSION}

This EAG analysis of the response of $L$. sativae to different plants demonstrates that the antennae of the leafminers respond selectively to host plant odours. They are more sensitive to host plants, such as bean and tomato, than they are to non-host plants such as Chinese rose and morning glory. Behavioural studies in the olfactometer produced analogous results (Zhao \& Kang, 2002b). Odours of host plants, such as bean and tomato, had similar levels of attraction to the leafminer, and were much more attractive than were the non-host plants. All the healthy plants, no matter whether host plants or nonhost plants, elicited higher magnitudes of response than did controls (Fig. 1). The green leaf volatiles (GLVs), which generally exist in green plants, may attract the polyphagous leafminer. When the plants were damaged mechanically, greater amount of plant volatiles, especially the green leaf volatiles, were released (Visser, 1979), which may contribute to the high EAG responses of $L$. sativae (Fig. 1). Previous studies have shown that $L$. sativae were more sensitive to green leaf volatiles and other characteristic volatiles of the host plants (Zhao \& Kang, 2002a). We suggest that the leafminer, L. sativae, employ both the GLVs and other characteristic volatiles of host plants in orientating to their host habitats. Behav-

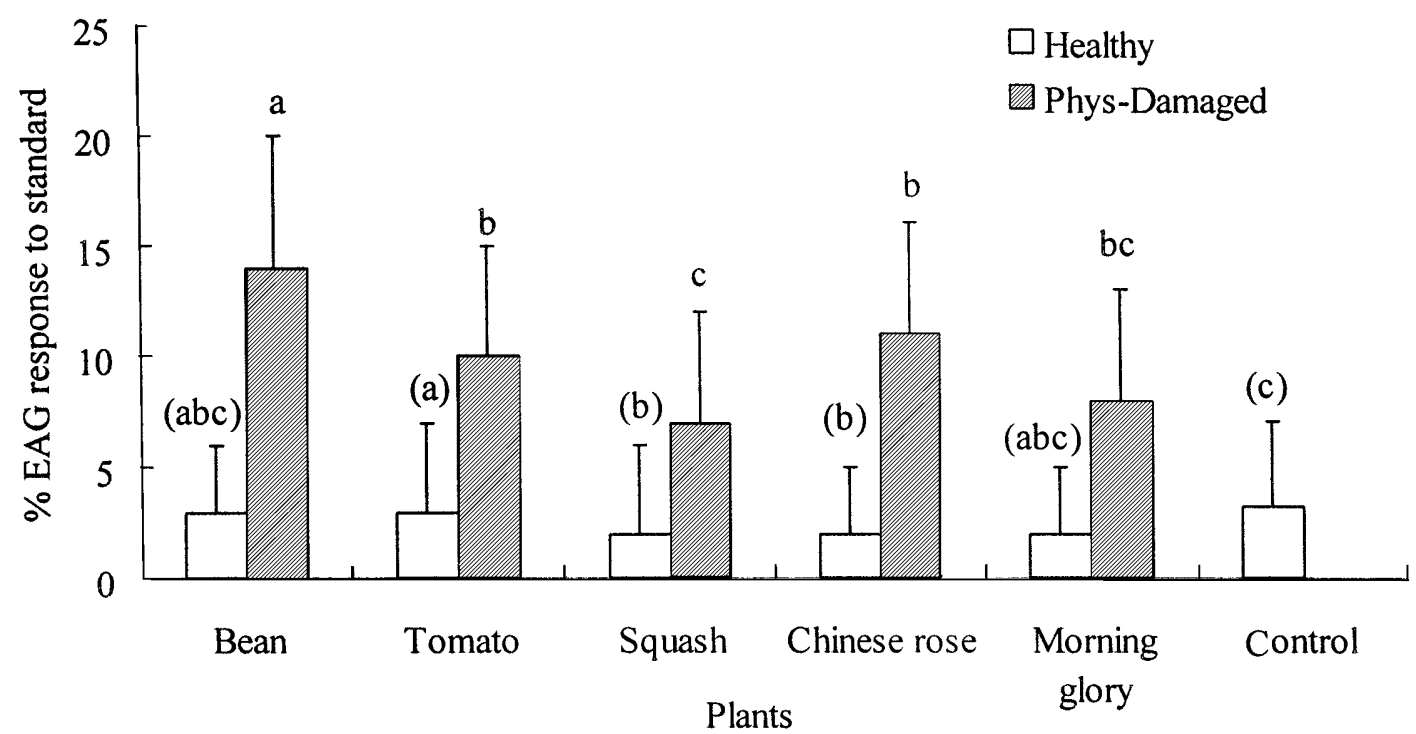

Fig. 2. EAG responses of female $D$. isaea to the odours of different plants $(\mathrm{n}=10)$. The vertical line indicates standard deviation. Letters within the brackets represent significant difference of EAG responses between healthy plants and controls. Letters without brackets represent significant difference of EAG responses to physically damaged plants. Means with the same letter on the bar are not significantly different $(P<0.05)$. 


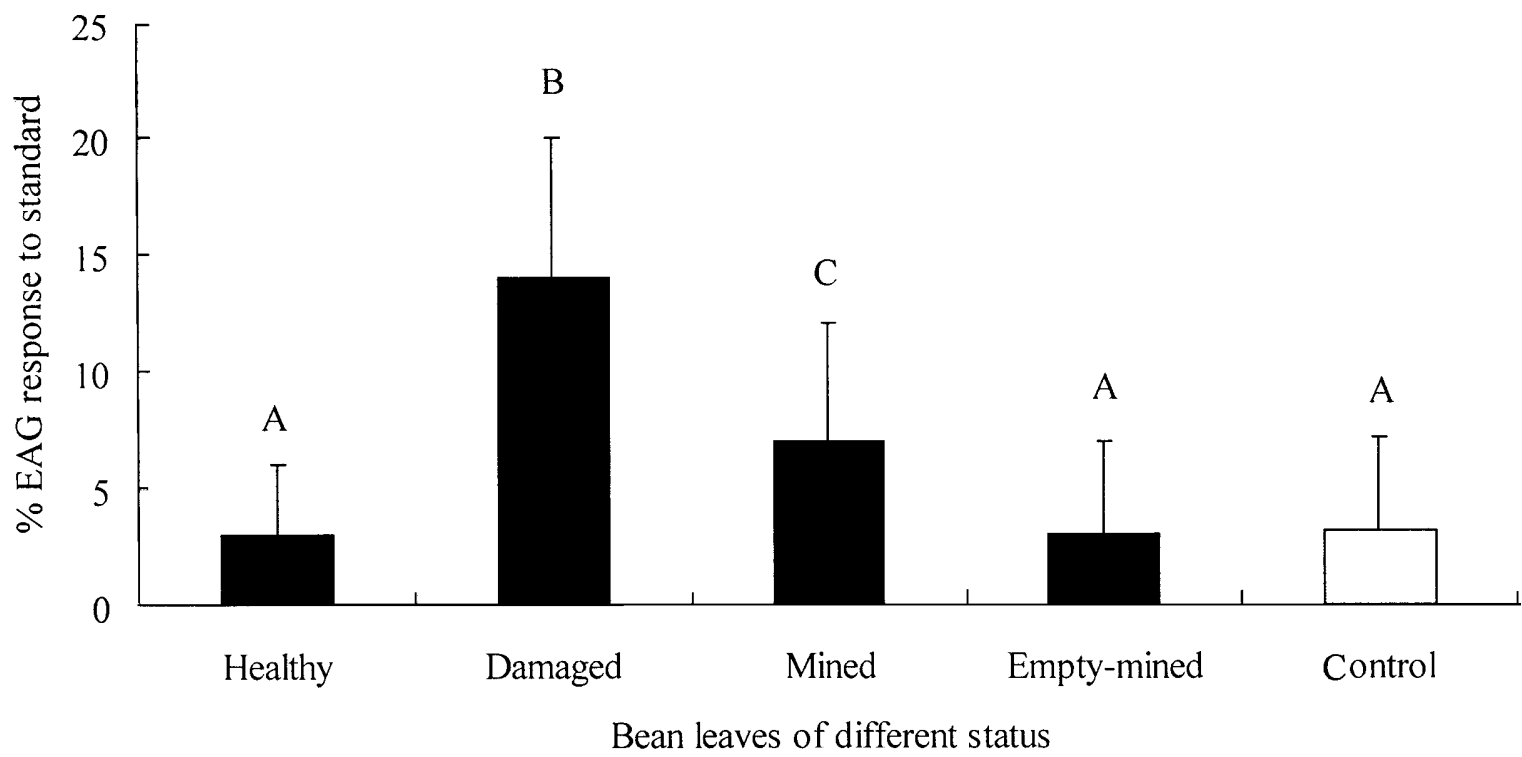

Fig. 3. EAG responses of $D$. isaea to the odours of bean in different status $(\mathrm{n}=10)$. The vertical line indicates standard deviation. Means with the same letter on the bar are not significantly different $(P<0.01)$.

ioural assays are needed to determine the effect of the GLVs and the characteristic volatiles of host plants on the leafminer.

In locating their hosts, parasitoids must search for potential hosts living on different plants growing in diverse habitats. Chemical stimuli act as the cues which direct many parasitoids to their hosts (Dicke \& Minkenberg, 1991). Some parasitoids use volatiles emitted by undamaged plants to locate the habitat and, possibly, the microhabitat of their host (Elzen et al., 1984; Ngi-Song et al., 1996). Two parasitoids Cotesia flavipes and Cotesia sesamiae were strongly attracted to odours emanating from several gramineous plants (maize, sorghum, and a wild host, napier grass), which are host plants of stemborers. Both of them had showed preferences for the host plants of their prey. C. flavipes showed a preference for maize over sorghum, while $C$. sesamiae was more attracted to sorghum odours (Ngi-Song et al., 1996). In the EAG analysis of $D$. isaea, none of the EAG responses to the odours of healthy plants differed from the controls, regardless of whether they were hosts or non-hosts of the leafminer (Fig. 2). The odours of mechanically damaged leaves elicited higher EAG responses than did intact leaves, which may be due to the higher quantities of the "green leaf volatiles" (GLVs) released by damaged leaves (Visser, 1979). No preferences of D. isaea to particular plants were detected in the EAG responses to the odours of healthy and physically damaged leaves. An early bioassay of $D$. isaea showed that the parasitoids were slightly attracted by the bean odour (Finidori-Logli et al., 1996). Larval and adult conditioning of $D$. isaea affected slightly the females' selection of plant type on which the host larvae were located (Coaker \& Cheah, 1993). In this study, D. isaea pupae were removed from the plants before their emergence. The adults had thus no experience with the plants, and no distinct EAG responses to odours of beans were detected. Whether they would have more sensitive EAG responses to host plants after conditioning remains to be investigated.

Physically damaged bean leaves elicited the most distinctive EAG responses in $D$. isaea, with mined leaves second. The odours of the mined leaves was more attractive behaviourally to the parasitoid than were the mechanically damaged leaves (Findori-Logli et al., 1996). The greater amount of GLVs in the mechanically damaged bean leaves may have little attraction to $D$. isaea, whereas the particular volatiles released by the mined leaves were attractive to the parasitoid. Plants may be induced to emit attractants utilized by insect parasitoids by the host saliva (Turlings et al., 1990). The volatile blends that are released in response to herbivore feeding are not identical to those elicited by artificial damage done by mechanical means (Dick \& van Loon, 2000). Two components, cis-3-hexen-1-ol and 4-hydroxy-4methyl-2-pentanone, were present in significantly larger quantities in the leaf extracts from mined or damaged bean plants than in those from healthy ones (FindoriLogli et al., 1996). The compound 1-Octen-3-ol was emitted only by the mined leaves (Findori-Logli et al., 1996). It is understood that the chemosensory system of arthropods is able to detect volatile compounds at concentrations that are so low that they escape attention in gaschromatographic mass spectrometric analyses (Pickett, 1990; Pickett et al., 1998). 1-Octen-3-ol may be only one of many herbivore-induced volatile (HIV) components. Whether 1-Octen-3-ol itself or the whole HIV blend has the attractive function needs further research. The EAG response of $D$. isaea to the odour of leaves with empty mines is similar to the healthy ones. This may be due to the cessation of HIV released when the herbivore stopped feeding. Although some parasitoids use volatiles emitted by undamaged plants to locate the habitat and possibly the microhabitat of their host, the HIVs were more important in guiding $D$. isaea to their hosts. We suggest that for 
successful establishment, the parasitoid should be released after the infestation of the plant by the leafminer.

The release of plant compounds is highly variable across plant species and varieties and is also sensitive to the species of the herbivore involved (Dicke et al., 1990; Turlings et al., 1990, 1991; Takabayashi et al., 1991; Röse et al., 1996; De Moraes et al., 1998). It is the herbivores that provide the parasitoids with the detectable and reliable cues in host location. De Moraes \& Lewis (1999) demonstrated that two parasitoids, Cardiochiles nigriceps (Vier.) and Microplitis croceipes (Cresson), both depend primarily on herbivore-induced signals, and these two species demonstrate a significant plant species preference: $C$. nigriceps for tobacco and $M$. croceipes for cotton. The leafminer is a polyphagous herbivore. Are there any differences in the leafminer-induced volatiles among the host plants? Can the parasitoid $D$. isaea select plants by discriminating among these volatiles? Comparative research on herbivore-induced volatiles of different plants and the behavioural responses of the parasitoid to them need to be continued.

ACKNOWLEDGEMENTS. We are grateful to Dr. Chao Dong Zhu (Institute of Zoology, Chinese Academy of Sciences) for identifying the parasitoid Diglyphus isaea. We also extend our thanks to the anonymous reviewers for their helpful comments. This research was supported by grants from the State Key Basic Research and Development Plan (Grant No. G2000016209), Chinese Academy of Sciences (KZ951-B1-106-2) and Agriculture Department of People's Republic of China (Grant No. 96005-01-12-3).

\section{REFERENCES}

AsKew R.R. \& SHAW M.R. 1978: Account of Chalcidoidea parasitizing leaf-mining insects of deciduous trees in Britain. Biol. J. Linn. Soc. 6: 289-335.

CoAker T.H. \& Chear C.A. 1993: Conditioning as a factor in parasitoid host plant preference. Biocontrol Sci. Tech. 3: 277-283.

Cosse A.A., Todd J.L., Mrllar J.G., Martinez L.A. \& Barker T.C. 1995: Electroantennographic and coupled Gas Chromatographic-Electroantennographic responses of the Mediterranean fruit fly, Ceratitis capitata, to male-produced volatiles and mango odour. J. Chem. Ecol. 21: 1823-1836.

De Moraes C.M., Lewis W.J. \& Tumuinson J.H. 2000: Examining plant-parasitoid interactions in tritrophic systems. Ann. Soc. Entomol. Brasil 29: 189-203.

De Moraes C.M. \& Lewis W.J. 1999: Analyses of two parasitoids with convergent foraging strategies. J. Insect Behav. 12: 571-583.

De Moraes C.M., Lewis W.J., Pare P.W., Alborn H.T. \& TumLINSON J.H. 1998: Herbivore-infested plants selectively attract parasitoids. Nature 393: $570-573$.

Dicke M. \& van LoON J.J.A. 2000: Multitrophic effects of herbivore- induced plant volatiles in an evolutionary context. Entomol. Exp. Appl. 97: 237-249.

Dicke M. \& Minkenberg O.P.J.M. 1991: Role of volatile infochemicals in foraging behavior of the leafminer parasitoid Dacnusa sibirica (Diptera: Agromyzidae). J. Insect Behav. 4: $489-500$.

Dicke M., Sabelis M.W., Takabayashi J., Brutn J. \& Posthumus M.A. 1990: Plant strategies of manipulating predator-prey interactions through allelochemicals: prospects for application in pest control. J. Chem. Ecol. 16: 3091-3118.

Elzen G.W., Williams H.J. \& Vinson S.B. 1984: Isolation and identification of cotton synomones mediating searching behavior by the parasitoid Campoletis sonorensis. J. Chem. Ecol. 10: 1251-1264.

Finidori-Logli V., Bagneres A.G. \& Clement J.L. 1996: Role of plant volatiles in the search for a host by the parasitoid Diglyphus isaea (Hymenoptera: Eulophidae). J. Chem. Ecol. 22: 541-558.

GUERIN P.M. \& VISSER J.H. 1980: Electroantennogram responses of the carrot fly, Psila rosae, to volatile plant components. Physiol. Entomol. 5: 111-119.

Johnson M.W. \& Hara A.H. 1987: Influence of host crop on parasitoids (Hymenoptera) of Liriomyza spp. (Diptera: Agromyzidae). Environ. Entomol. 16: 339-344.

KANG L. 1996: Ecology and Sustainable Control of Serpentine Leafminers. Science Press, Beijing, 215pp. [in Chinese]

Light D.M., JANG E.B. \& Dickens J.C. 1988: Electroantennogram responses of the mediterranean fruit fly, Ceratitis capitata, to a spectrum of plant volatiles. J. Chem. Ecol. 14: $159-180$.

MinKenberg O.P.J.M. \& van Lenteren J.C. 1986: The leafminer Liriomyza bryoniae and L. trifolii (Diptera: Agromyzidae), their parasites and host plants: a review. Agricultural University Wageningen Papers. Agricultural University Wageningen, The Netherlands, Vol. 86: $50 \mathrm{pp}$.

Ngi-Song A.J., Overholt W.A., Niagi P.G.N., Dicke M., Ayertey J.N. \& LWANDE W. 1996: Volatile infochemicals used in host and host habitat location by Cotesia flavipes (Cameron) and Cotesia sesamiae (Cameron) (Hymenoptera: Braconidae), larval parasitoids of stemborers on Graminae. $J$. Chem. Ecol. 22: 307-323.

Parrella M.P. 1987: Biology of Liriomyza. Annu. Rev. Entomol. 32: 201-224.

PICKETT J.A. 1990: Gas chromatography-mass spectrometry in insect pheromone identification: three extreme case histories. In: McCaffery A.R. \& Wilson I.D. (eds), Chromatography and Isolation of Insect Hormones and Pheromones. Plenum Press, New York, pp. 299-309.

Pickett J.A., Wadhays L.J. \& WoodCock C.M. 1998: Insect supersense. Mate and host location by insects as model systems for exploiting olfactory interaction. The Biochemist 1998 (Aug.): 8-13.

Röse U.S.R., Manukian A., Heath R.R. \& Tumlison J.H. 1996: Volatile semiochemicals released from undamaged cotton leaves: A systemic response of plants to caterpillar damage. Plant Physiol. 111: 487-495.

Salvo A. \& Valladares G.R. 1997: An analysis of leaf-miner and plant host ranges of three Chrysocharis species (Hym.: Eulophidae) from Argentina. Entomophaga 42: 417-426.

Schuster D.J., Gilreath J.P., Wharton R.A. \& Seymour P.R. 1991: Agromyzidae (Diptera) leafminers and their parasitoids in weeds associated with tomato in Florida. Environ. Entomol. 20: 720-723.

Takabayashi J., Dicke M. \& Posthumus M.A. 1991: Variation in composition of predator attracting allelochemicals emitted by herbivore-infested plants: relative influence of plant and herbivore. Chemoecology 2: 1-6.

Turling T.C.J., Tumlinson J.H., Eller F.J. \& LeWis W.J. 1991: Larval-damaged plants: Source of volatile synomones that guide the parasitoid Cotesia marginiventris to the microhabitat of its hosts. Entomol. Exp. Appl. 58: 75-82.

Turling T.C.J., Tumlinson J.H. \& Lewis W.J. 1990: Exploitation of herbivore induced plant odours by host seeking parasitic wasps. Science 250: 1251-1253. 
Van Lenteren J.C. \& Woet J. 1988: Biological and integrated pest control in greenhouses. Anmu. Rev. Entomol. 33: 239-269.

VISSER J.H. 1979: Electroantennogram responses of the colorado beetle Leptinotarsa decemlineata to plant volatiles. Entomol. Exp. Appl. 25: 86-97.

ZehNder G.W. \& Trumble J.T. 1984: Host selection of Liriomyza species (Diptera: Agromyzidea) and associated parasites in adjacent plantings of tomato and celery. Environ. Entomol. 13: 492-496.

ZhaO Y.X. \& Kang L. 2002a: Role of plant volatiles in host plant location of the leafminer, Liriomyza sativae (Diptera: Agromyzidae). Physiol. Entomol. 27: 103-111.
Zhaо Y.X. \& Kang L. 2002b: Olfactory responses of the leafminer Liriomyza sativae (Diptera: Agromyzidae) to the odours of host and non-host plants. J. Appl. Entomol. (in press).

ZHAO Y.X. \& KANG L. 2001: Improvement of electroantennogram technique for dipteran flies. Entomol. Knowledge 38: 386-387. [in Chinese]

ZhaO Y.X. \& Kang L. 2000: Cold tolerance of the leafminer Liriomyza sativae (Dipt.: Agromyzidae). J. Appl. Entomol. 124: 185-189.

Received November 11, 2001; revised January 7, 2002; accepted May 6, 2002 